\title{
Evaluation of ecological suitability of rural tourism land - a case study of Xi'an city
}

\author{
FAN Bing ${ }^{1}$ and $Y A N G$ Wei-li ${ }^{1}$ \\ ${ }^{1}$ Northwestern Polytechnical University, Xi'an 710129, Shaanxi, China
}

\begin{abstract}
Ecological suitability evaluation is an important prerequisite for rational distribution of tourism. Take Xi'an as an example, selecting six factors as evaluation indexes: elevation, slope, vegetation coverage, river, landscape quality and traffic. After using RS, GIS techniques and resorting to factor weighted superposition method and obtaining the results. The results show that the most suitable, suitable, basic suitable, unsuitable and unavailable land of Xi' an rural tourism respectively account for $17.5 \%, 25.4 \%, 20.63 \%$, $22.12 \%$ and $14.35 \%$. According to the distribution pattern of different suitability, the corresponding land use measures are put forward for development of rural tourism in Xi'an city, which provides a theoretical basis for Xi'an to explore the coordinated path of ecological protection and economic development.
\end{abstract}

Man-land relationship has always been an important scientific issue in geography, ecology, urban planning and other fields. Especially when population is growing rapidly, environment and resources are under great pressure and crisis. Specifically, the relationship between man and land is mainly the "mutual inductance" ${ }^{[1]}$ relationship between human socio-economic activities and ecological resources such as land and spaces. Rural tourism is a new growth point of rural economic development under the "New Normal". It can help effectively solve the "three-agriculture" issue and promote the construction of beautiful rural and ecological civilization ${ }^{[2]}$. Based on the perspective of human-land relationship, sensing rural ecological environment is significant for providing exploration path for rural tourism.

Land evaluation is an assessment of the land potential based on land attributes ${ }^{[3]}$. The land property is different, just as D.G Rossiter believes, "land is born unequal". Land use is also different. "Suitability" can evaluate the degree of satisfaction of different ways of land. Land attributes are varied, and the factors affecting them are plenty. In recent years, the maturity of Geographic Information System (GIS) and Remote Sensing technology (RS) has promoted the development of urban land suitability evaluation ${ }^{[4]}$. Different index selection, weight judgment and model construction will produce different evaluation results.

In the Review of the study of evaluation of land ecological suitability, the land has been transformed from surface plane to stereoscopic space, from a single natural attribute to multiple attributes of ecology and socio-economic. The meaning of ecology is more complicated, which requires hierarchical, representative and comprehensive index construction.

\section{Research areas and data sources}

\subsection{Research areas}

Xi'an is located in the middle of Guanzhong Plain, the northern foothills of Qinling Mountains. (Shown in Figure.1) The profound historical and cultural accumulation and the vast legacy of monuments make Xi'an enjoy the reputation of "Natural History Museum". From south to north Xi'an consists of the shallow mountain hilly area in the northern foothills of Qinling Mountains, the comprehensive development Zone of Guanzhong Plain, the low-lying area of Wei River main Stream valley and the Loess Plateau area of Weibei ${ }^{[5]}$.The Ba, Chan, Jing, Feng, Lao, Yu and Hao Rivers form a drainage system from east to West. Relying on the above humanistic and ecological resources, rural tourism in the suburban area of $\mathrm{Xi}$ 'an is developing rapidly, but also facing the problems of declining environmental quality, dislocation of land use and low utilization of resources.

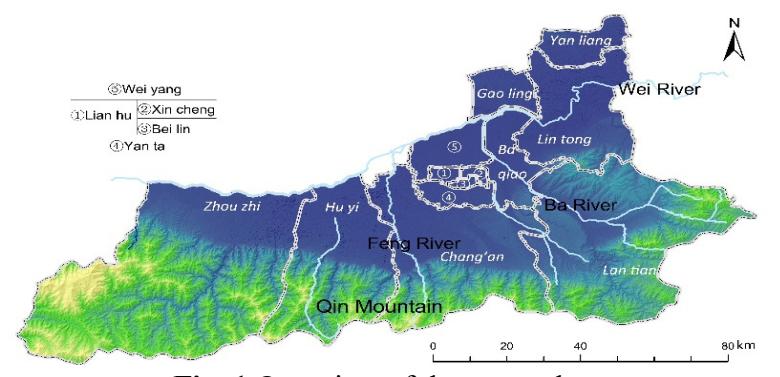

Fig. 1 Overview of the research area

\subsection{Research data}

(1) RS data: Landsat8 satellite images, obtained by Operational Land Image with a resolution of $30 \mathrm{~m}$, cloud cover below 10, receiving time from June to July 2016, vegetation growth is vigorous. ENVI5.2 and ArcGIS10.3 are used to preprocess the image, such as radiation cor- 
rection, atmospheric correction and so on. Referring to the Land use status Distribution (GB/T21010- 2017) issued in November 2017, combined with the specific land use situation. Land use in the study area is divided into farmland, garden land, forest land, water area and construction land. (2) Digital elevation model data (DEM), obtained by Geospatial Data Cloud.

\section{Research methods and steps}

\subsection{Acquisition of single factor evaluation in- formation}

(1) Slope

It is as an important control parameter that affects the investment of rural tourism project construction and the intensity of rural resource exploitation. In the southern part of the study area, the mountainous area with slopes above 25 degrees is $5319.64 \mathrm{~km}^{2}{ }^{[6]}$. The data of DEM obtained from Geospatial Data Cloud platform is used to generate the slope by the Spatial Analyst tool in ArcGIS.

\section{(2) Elevation}

This is the measure of elevation ecological sensitivity. The study area has complex topography and diverse landscape. Xi'an has a vast mountainous area, and elevation is an important control item in the scope of ecological protection in Qinling Mountains, which is used to limit development behavior.

(3) Vegetation coverage

It is an indicator of the ecosystem diversity, the landscape abundance, and is an important index of rural tourism ecological resource endowment. In this study, vegetation index was used as indicator to reflect the growth and coverage of vegetation on the surface. This study uses Normalized Vegetation Index (NDVI) to estimate vegetation coverage. The formula of NDVI is:

$$
\mathrm{NDVI}=\frac{N I R-\text { Red }}{N I R+\text { Red }}
$$

In this formula, NIR is the reflectivity value of near-infrared band. $\mathrm{R}$ is the infrared band reflectivity value.

\section{(4) Distance from major rivers}

River is an important linear element in landscape ecosystem, which enhances the interest and flexibility of space. However, construction is easy to cause urban flood and water pollution, which can resulted in enormous economic loss, serious threat to human security. Extracting the linear vector data of rivers crawling from Open Street Map in QGIS platform. The distribution of river is obtained by correcting the vector data of rivers based on present situation of river interpreting by RS. Based on the Distance Analysis in ArcGIS10.3, the Euclidean distance of the channel is calculated, and the distance distribution of the main river is formed.

(5) Landscape Ecological Quality

Study on the Present Situation of Land Use often neglect the influence of the spatial pattern of land use on the ecological process ${ }^{[7]}$. Rural tourism is mostly laid out the urban fringe, where the ecosystem is fragile, and the ability to resist the human activity interference is weak. This study introduces landscape pattern index, and con- stitutes Landscape Ecological Quality (LEQ) by superposition calculation of different indices.(shown in table 1) LEQ reflects the comprehensive impact on the ecological environment system caused by many factors, such as nature and man, in the region.

Tab.1 Landscape pattern indices

\begin{tabular}{|c|c|}
\hline indices & Formula and Description \\
\hline $\begin{array}{l}\text { Landscape } \\
\text { Fragmentation } \\
\quad \text { Index } C_{i}\end{array}$ & $\begin{array}{c}C_{i}=n i / A_{i}, \text { Its value expresses the fragmen- } \\
\text { tation degree of a certain landscape, and the } \\
\text { landscape disturbed by human tends to be } \\
\text { complex, heterogeneous patch mosaics }\end{array}$ \\
\hline $\begin{array}{l}\text { Landscape } \\
\text { Abruption } \\
\text { Index } F_{i}\end{array}$ & $\begin{array}{l}F_{i}=D_{i} / S_{i}, D_{i}=1 / 2 \sqrt{n i / A}, S_{i=} A_{i} / A, \\
\text { Landscape Abruption is the degree of sepa- } \\
\text { ration of individual distribution of different } \\
\text { patches in a certain landscape type }\end{array}$ \\
\hline $\begin{array}{l}\text { Landscape } \\
\text { Fractal } \\
\text { Index } S_{i}\end{array}$ & $\begin{array}{l}\text { Use the Area-weighed Mean Fractal } \\
\text { Dimension refer to } S_{i} \text {, AWMPFD is an } \\
\text { index to measure the complexity of land- } \\
\text { scape space shape, which is influenced by } \\
\text { human }\end{array}$ \\
\hline
\end{tabular}

ni for Landscape type $i$ number of patch; $A_{i}$ for Landscape type $i$ area; $A$ for landscape total area; $S_{i}=\left(S_{i}-S_{i, \min }\right) /\left(S_{i, \max }-S_{i, \min }\right)$, These indices are all negative indices, so $\mathrm{LEQ}=1 /\left(C_{i}+F_{i}+S_{i}\right)$

(6) Distance from the main traffic lines

Distance from the traffic line is a contradictory factor in the evaluation of ecological suitability of rural tourist land. Its positive significance is reflected in the convenience brought by the traffic line, at the same time, the traffic line has a strong interference to the landscape ecology, which brings displeasure to people's visual senses and psychological feelings, and produces noise pollution. Based on the ArcGIS10.3 platform, this study uses the road vector map of the study area to select the motorway, expressway, primary way to calculate its Euclidean distance, then the raster reclassification, from the road midline 200 meters range to consider its ecological negativity, 200 meters beyond the consideration of its traffic convenience.

\subsection{Factor weight determination}

Using Analytic Hierarchy Process (AHP) to determine the weight of evaluation factors in this study, AHP is a simple method for quantitative analysis of non-quantitative things in system engineering. The various complex factors are expressed in the form of hierarchical structure and analyzed layer by layer.

Taking the geographical environment, ecological landscape, man-made influence as the middle layer, connecting the decision-making and index layers, together constitute the ecological suitability evaluation system of rural tourist land. Using Delphi method to discuss the relative importance of elements of the middle layer and the index layer, as shown in Figure 2, the weight of the factor is obtained. Random Consistency Ratio $\mathrm{CR}=0.0516<0.10$ to meet testing. 


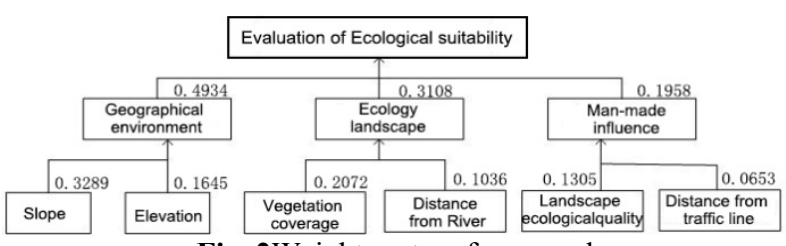

Fig. 2Weight system framework

\subsection{Evaluation model of ecological suitability}

The evaluation model as follows:

$$
S_{i}=\sum_{k=1}^{n} w_{k} \times C_{i}(k)
$$

In the formula, $i$ is the raster number; $k$ is the evaluation factor number; $n$ is the total number of evaluation factors; $S_{i}$ is the comprehensive evaluation value of the first grid, and $w_{k}$ is the weight of the $k$ factor; $C_{i}(k)$ is the value of the evaluation factor suitability for the $\mathrm{K}$ of the first grid.

According to the single Factor evaluation standard, each factor is divided into five levels, which are assigned according to $9,7,5,3,1$ respectively.

\section{Research results}

\section{1 results of single factor evaluation}

\section{(1) Elevation}

According to the DEM analysis of Xi'an digital elevation model, the lowest elevation of Xi'an is 207 meters and the highest elevation is 3754 meters. The altitude of 800 meters above the mountain area is 4865.234 square kilometers, accounting for $48 \%$ of the land area of $\mathrm{Xi}$ ' an. Mountain area is broad, the contradiction between ecological benefit and economic benefit is sharp. That is the main problem of urban construction in Xi'an, and is also the main bottleneck of rural tourism development. (Shown as Fig.3)

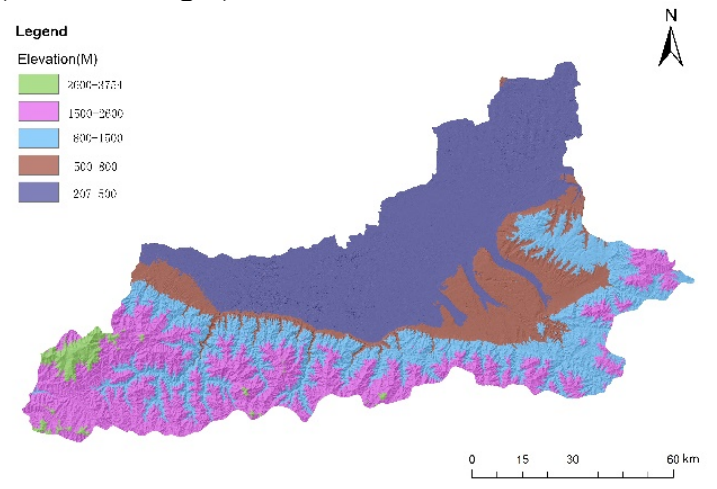

Fig. 3 Elevation classification

(2) Slope

Based on DEM of Xi'an, ArcGIS platform is used to calculate the slope. The area with slope above 25 degree in Xi'an is $2910.223 \mathrm{~km}^{2}$, accounting for $28.7 \%$ of the land area of Xi'an, and it is not suitable for construction. Intersecting analysis of land use type and slope in ArcGIS platform found that the construction land with slope above 25 degree is $195.6 \mathrm{~km}^{2}$, accounting for $6.1 \%$ of the total construction land.(Shown as Fig.4)

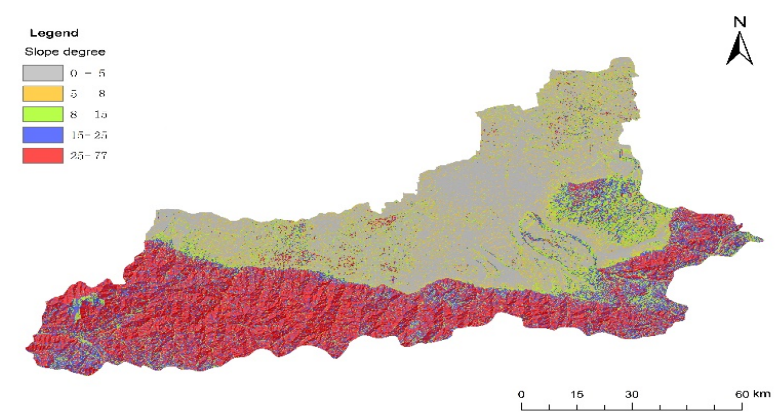

Fig. 4 Slope classification

(3) Vegetation coverage

In order to facilitate the subsequent weighting operation, the NDVI is stretched from $[-1,1]$ to a gray scale value of 0 to 255 , and a classification method is used to classify NDVI based on the mean and standard deviation of the gray scale value pixels, and the greater the value indicates the greater the vegetation coverage.

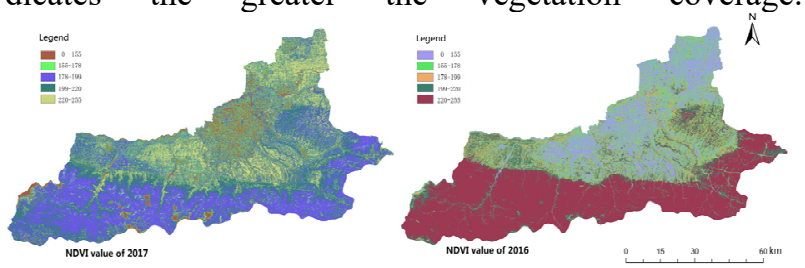

Fig. 5 NDVI Comparison of 2016,2017

Xi'an large area of cultivated land mainly grows winter wheat, summer harvest. Based on the acquisition of Landsat 8 satellite imagery, in terms of meeting cloud cover below 20\%, the imaging date is between April and October (vegetation growth season), this study selected April to May(2017) images, June to July (2016)images for related research. The NDVI shows that there is a large area of wasteland in the wheat harvest season, and the vegetation cover is not representative at the bottom. Therefore, the 2017 NDVI was selected to indicate vegetation coverage.(Shown as Fig.5)

(4) Distance from major rivers

"Eight rivers moisten Xi'an" is the real description of the river system pattern in Xi'an, the Ba, Chan, Jing, Feng, Lao, Yu and Hao rivers in the north and south direction of the development of East and West vertical arrangement, Wei River East-west flow, the first tributary together with the two or three-stage tributary, together constitute a887.7848 Kilometer-long "comb" water system network. Based on the river linear vector data obtained from OSM, the current situation of land use in river waters is obtained by $\mathrm{RS}$ interpretation, and the river buffer is generated by ArcGIS10.3 platform.(Fig.6)

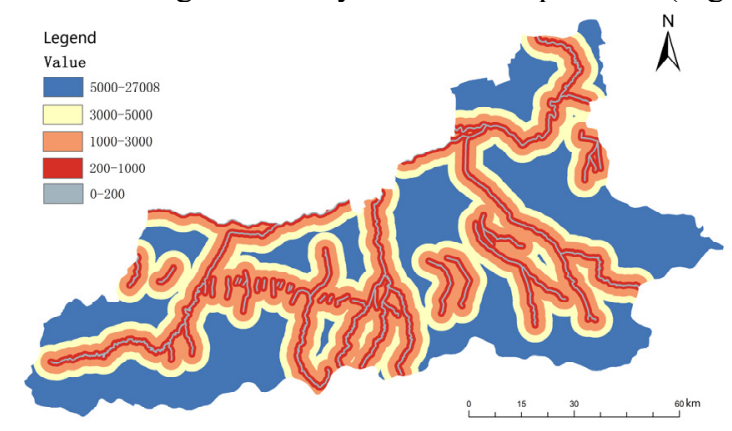

Fig. 6 Distance from major rivers 
(5) Landscape Ecological Quality

Using Fragststs 4.2 to calculate the landscape pattern index. It can be seen from the table that the frost land area of Xi'an is large, the number of patches is small, the degree of Landscape Fragmentation and Abruption are small. That is because the forest land is mainly distributed in Qinling Mountains on a large scale, less human interference and the ecological environment is stable. The area of construction land is second only to frost land area with a largest number of patches, but its Landscape Fragmentation and Abruption degree are small, which is due to human continuous development and construction causing a density construction, connecting scattered patch into pieces, which is simple, monotonous and universal. The water land is small but the patch number is large, and its Fragmentation and Abruption degree is larger. That is mainly because the aquiculture occupation, which is obvious in the rural tourism land because there are all kinds of leisure agriculture.

Tab. 2 Landscape pattern index

\begin{tabular}{cccccc}
\multicolumn{5}{c}{ Tab. 2 Landscape pattern index } \\
\hline $\begin{array}{c}\text { landscape } \\
\text { type }\end{array}$ & Area/m2 & $\begin{array}{c}\text { Patch } \\
\text { Number }\end{array}$ & $C_{i}$ & $F_{i}$ & $S_{i}$ \\
\hline $\begin{array}{c}\text { Construction } \\
\text { land }\end{array}$ & 318037.6 & 18896 & 0.0594 & 0.2173 & 1 \\
garden land & 76681.1 & 14301 & 0.1865 & 0.7840 & 0.4440 \\
Water land & 28993.3 & 15861 & 0.5471 & 2.1836 & 0 \\
Frost land & 476592.9 & 4140 & 0.0087 & 0.0679 & 0.6422 \\
farmland & 110534.7 & 9368 & 0.0848 & 0.4402 & 0.4109 \\
\hline
\end{tabular}

(6) Distance from the main traffic lines

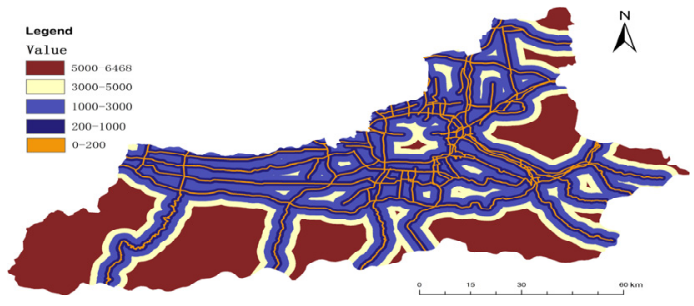

Fig. 7 Distance from the main traffic lines

Distance from the main lines of transport based on the acquisition of linear traffic network data from OSM data, three road levels of motorway, expressway, primary way are needed. Extract the road centerline and calculate the mileage of each level of road $(\mathrm{km})$. As of 2017, Xi'an has 542.9018 kilometers of motorway, 190.531 kilometers of expressway, and 1112.5967 kilometers of primary way. As can be seen from the figure (7), the roads in the central urban areas of Xi'an are reticulated, while the urban fringe areas are simply transverse parallel arrangement, with some vertical lines of transport.

\subsection{Comprehensive evaluation results of eco- logical suitability}

Based on the evaluation model of rural tourism land suitability, the suitability evaluation is completed by ARCGIS10.3 platform according to the score and weight assigned as the Table.3.

In the ArcGIS platform, six single vectorization factors are rasterized, the image is 50 meters long, and using the weighted sum in the spatial Analyst tool to calculate the results, as shown in the figure (8)
Tab. 3 Single factor classification

\begin{tabular}{|c|c|c|c|c|}
\hline Order & Factors & Level & Score & Weight \\
\hline \multirow{5}{*}{1} & \multirow{5}{*}{ Elevation } & $207 \sim 500$ & 9 & \multirow{5}{*}{0.3289} \\
\hline & & $500 \sim 800$ & 7 & \\
\hline & & $800 \sim 1500$ & 5 & \\
\hline & & $1500 \sim 2600$ & 3 & \\
\hline & & $2600 \sim 3754$ & 1 & \\
\hline \multirow{5}{*}{2} & \multirow{5}{*}{ Slope } & $0 \sim 5$ & 9 & \multirow{5}{*}{0.1645} \\
\hline & & $5 \sim 8$ & 7 & \\
\hline & & $8 \sim 15$ & 5 & \\
\hline & & $15 \sim 25$ & 3 & \\
\hline & & $25 \sim 77$ & 1 & \\
\hline \multirow{5}{*}{3} & \multirow{5}{*}{$\begin{array}{l}\text { Vegetation } \\
\text { coverage }\end{array}$} & $220 \sim 255$ & 9 & \multirow{5}{*}{0.2072} \\
\hline & & $199 \sim 220$ & 7 & \\
\hline & & $178 \sim 199$ & 5 & \\
\hline & & $155 \sim 178$ & 3 & \\
\hline & & $0 \sim 155$ & 1 & \\
\hline \multirow{5}{*}{4} & \multirow{5}{*}{$\begin{array}{l}\text { Distance from } \\
\text { major rivers }\end{array}$} & $0 \sim 200$ & 3 & \multirow{5}{*}{0.1036} \\
\hline & & $200 \sim 1000$ & 9 & \\
\hline & & $1000 \sim 3000$ & 7 & \\
\hline & & $3000 \sim 5000$ & 5 & \\
\hline & & $5000 \sim 27008$ & 1 & \\
\hline \multirow{5}{*}{5} & & Construction land & 5 & \multirow{5}{*}{0.1305} \\
\hline & Landscape & garden land & 3 & \\
\hline & Ecological & Water land & 1 & \\
\hline & Quality & Frost land & 9 & \\
\hline & & farmland & 7 & \\
\hline \multirow{5}{*}{6} & & $0 \sim 200$ & 3 & \multirow{5}{*}{0.0653} \\
\hline & Distance from & $200 \sim 1000$ & 9 & \\
\hline & the main & $1000 \sim 3000$ & 7 & \\
\hline & traffic lines & $3000 \sim 5000$ & 5 & \\
\hline & & $5000 \sim 6468$ & 1 & \\
\hline
\end{tabular}

\subsection{Result analysis}

The suitability rating shows, shown as the figure8,that the most suitable land, suitable land and basic suitable land total $6265.027 \mathrm{~km} 2$, accounting for $63 \%$ of the city area, indicating that $\mathrm{Xi}^{\prime}$ an has the potential to develop rural tourism. However, due to the ecological value of Qinling Mountains and Li Mountains, the development of rural tourism should focus on the contradictory relationship between development and protection.

Tab. 4 Evaluation results and feature

\begin{tabular}{ccc}
\hline Rating & Score & \multicolumn{1}{c}{ feature } \\
\hline $\begin{array}{c}\text { The most } \\
\text { suitable }\end{array}$ & $(7.2,9]$ & $\begin{array}{c}\text { Strong ecological self-healing ability, strong } \\
\text { immunity of external environment to human } \\
\text { destruction }\end{array}$ \\
suitable & $(6.1,7.2]$ & $\begin{array}{c}\text { Strong ecological self-healing ability, Ecolog- } \\
\text { ical cost of land development and utilization is } \\
\text { low }\end{array}$ \\
$\begin{array}{c}\text { Basic } \\
\text { suitable }\end{array}$ & $(5,6.1]$ & $\begin{array}{c}\text { The ecological environment potential is more } \\
\text { barren, the ecological environment is more } \\
\text { sensitive, can only carry on the conditional } \\
\text { development behavior }\end{array}$ \\
$\begin{array}{c}\text { Unsuitable } \\
\text { Not }\end{array}$ & $(4,5]$ & $\begin{array}{c}\text { Fragile ecological environment, difficult eco- } \\
\text { logical restoration, prohibition of development } \\
\text { and construction }\end{array}$ \\
available & $(1.5,4]$ & $\begin{array}{c}\text { Extremely fragile ecological environment, } \\
\text { extremely difficult ecological restoration, } \\
\text { prohibition of development and construction }\end{array}$ \\
\hline
\end{tabular}

(1) The Most Suitable Land for use

$1725.887 \mathrm{~km}^{2}, 17.50 \%$ of the total city area. Most of them are low-lying areas below 500 meters above sea level. At present, the type of land use is mainly high-quality farmland and orchards, which is an important resource for the development of rural tourism. This places close to the river network, away from urban construction areas, having a better quality of ecological landscape. The most suitable land is mainly located in the flat area extended from the northern foothills of Qinling Mountains. These places have a good environment 
and a low ecological sensitivity, are extremely suitable for the development of rural tourism.

(2) Suitable Land for use

$2504.69 \mathrm{~km}^{2}, 25.4 \%$ of the total city area. Construction land is mainly concentrated in it. This places have a small slope and low ecological sensitivity. Some of the land is distributed in the shallow mountain and gentle slope of the northern foothills of Qinling Mountains, with a good ecological quality and satisfying traffic conditions. But it is necessary to guide the development of this area reasonably and pay attention to the coordination of ecological damage and ecological compensation. Most suitable land and construction land blends miscellaneous, in the region to develop rural tourism should adhere to the fragmentation layout, to create a distinctive brand and extremely against the large-scale, low connotation, high energy consumption construction activities.

(3) Basic suitable land for use

$2034.45 \mathrm{~km}^{2}, 20.63 \%$ of the total. It is mainly along the Qinling Mountains and Li Mountains of the low and even valley with the slope is mainly between 15 to 25 degrees. And there are some in the loess tableland with the elevation between 500 to 800 meters. There are some rural built-up areas in the valleys and mountain basins of Qinling Mountains and Li Mountains, with high vegetation cover and excellent ecological landscape quality. And rural tourism can be developed after strict environmental compensation measures and planning approval. Traffic accessibility is an important limiting factor for the development of rural tourism in this area.

(4) Unsuitable land

$2180.9305 \mathrm{~km}^{2}, 22.12 \%$ of the total. They are mainly distributed at altitudes of 800 to 1500 meters, with slope greater than 25 degree. Its ecological environmental is very sensitive. This area is an important water source in Xi'an City. From the point of view of ecological protection, the region should strictly control the development and construction behavior.

(5) Not available

$1414.9395 \mathrm{~km}^{2}, 14.35 \%$ of the total. Mainly distributed in the depths of the Qinling Mountains, where the ecosystem is the worst stable and highly susceptible to interference by the external environment. It is an important animal-plant nature reserve and water source protection, which undertaking the function of ecological service.

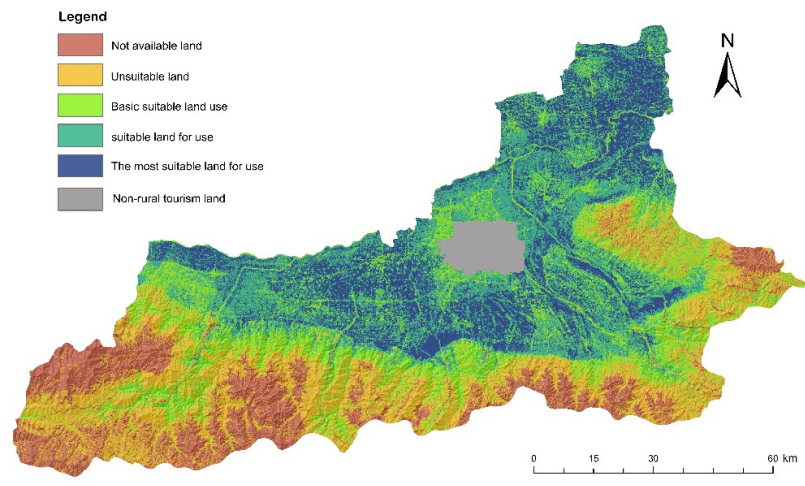

Fig. 8 Evaluation Results

\section{Conclusion}

Based on the characteristics of rural tourism and the objective characteristics of ecological environment, this study establishes an evaluation system of land ecological suitability by GIS and ENVI. Finally, the weighted sum analysis of each factor is carried out, and the evaluation result of ecological suitability of rural tourism land in $\mathrm{Xi}^{\prime}$ an is obtained.

Nearly one-third of the land area of $\mathrm{Xi}^{\prime}$ an is the Qinling Mountains region. These are main problems that how to innovate coordination path between development and protection, how to excavate the ecological agricultural resources, and how to stimulate the green economy development in the deep mountain , facing of $\mathrm{Xi}$ ' an. As an important economic model in the suburbs of $\mathrm{Xi}$ ' an, rural tourism has some problems, such as chaos of land use, waste of land resources, encroachment on ecological land and inadequate use of suitable land. And the final part of this study provides an exploration way for the solution of the above problems.

Sponsored by the Seed Foundation of Innovation and Creation for Graduate Students in Northwestern polytechnical University

\section{References}

1. Guan RuiMing. The relationship between man and land in the consciousness of building creation .J. CCA, 1 79-82. (2002)

2. Huang ZhenFang. The development of rural tourism under the background of new urbanization .J. GS, 8,1409-1421. (2015)

3. David G. Rossiter.A theoretical framework for land evaluation.Geoderma, 72, 165-190.(1996)

4. Li You, Wang Yanglin, Peng Jian. Evaluation of suitability of urban land development based on landscape ecology-a case study of Dandong .J. Ecology, 8, 2141-2150. (2010)

5. Xi'anCity master plan for the fourth time (2008-2020).XAUPDA. (2009)

6. Lu XiangHua, Ma XiFeng, Cao Kai Ning. Probe into the ecological environmental protection planning .J. Planner, (2015).1. 101-108

7. Qi Wei,OXianBo, Liu HongYi, LiLe. Regional representative Landscape Pattern index screening and land use zoning. J. LSIC, 23, 33-37. (2009) 